\title{
Endothelial nitric oxide synthase in the microcirculation
}

\author{
Xiaohong Shu ${ }^{1,2} \cdot$ T. C. Stevenson Keller IV ${ }^{2,3} \cdot$ Daniela Begandt ${ }^{2}$. \\ Joshua T. Butcher ${ }^{2}$ Lauren Biwer ${ }^{2,3} \cdot$ Alexander S. Keller $^{2,4}$. \\ Linda Columbus ${ }^{5} \cdot$ Brant E. Isakson $^{2,3}$
}

Received: 2 June 2015/Revised: 21 July 2015/Accepted: 11 August 2015/Published online: 25 August 2015

(C) Springer Basel 2015

\begin{abstract}
Endothelial nitric oxide synthase (eNOS, NOS3) is responsible for producing nitric oxide (NO)-a key molecule that can directly (or indirectly) act as a vasodilator and anti-inflammatory mediator. In this review, we examine the structural effects of regulation of the eNOS enzyme, including post-translational modifications and subcellular localization. After production, NO diffuses to surrounding cells with a variety of effects. We focus on the physiological role of $\mathrm{NO}$ and NO-derived molecules, including microvascular effects on vessel tone and immune response. Regulation of eNOS and NO action is complicated; we address endogenous and exogenous mechanisms of NO regulation with a discussion of pharmacological agents used in clinical and laboratory settings and a proposed role for eNOS in circulating red blood cells.
\end{abstract}

Keywords Endothelial nitric oxide synthase ·

Nitric oxide $\cdot$ Endothelium $\cdot$ Microcirculation

X. Shu and T. C. Stevenson Keller IV contributed equally to this work.

Brant E. Isakson

brant@virginia.edu

1 College of Pharmacy, Dalian Medical University, Dalian 116044, China

2 Robert M. Berne Cardiovascular Research Center, University of Virginia School of Medicine, P.O. Box 801394, Charlottesville, VA 22908, USA

3 Department of Molecular Physiology and Biophysics, University of Virginia School of Medicine, Charlottesville, USA

4 Department of Pharmacology, University of Virginia School of Medicine, Charlottesville, USA

5 Department of Chemistry, University of Virginia, Charlottesville, USA

\section{Introduction}

Nitric oxide (NO) is produced by a family of enzymes called nitric oxide synthases (NOS). There are three NOS isoforms, neuronal NOS (nNOS; NOS1), inducible NOS (iNOS; NOS2), and endothelial NOS (eNOS; NOS3), all of which differ slightly in physiological role and expression profile. nNOS is expressed in neurons and skeletal muscle and produces $\mathrm{NO}$ as a cellular signaling molecule. iNOS is expressed in immune cells and produces $\mathrm{NO}$ as a precursor to cytotoxic free radicals for defense against invading bacteria. This review focuses on eNOS, which is expressed in endothelial cells, and its role in vascular function. NO and its metabolites are found in both the macrovascular (aorta and medium arteries) and microvascular (arterioles/resistance arteries and capillaries) circulation. Endothelialderived $\mathrm{NO}$ acts as a potent vasodilator through diffusion to smooth muscle cells that surround vessels and decreases leukocyte adhesion to the endothelial cells, thereby affecting immune response and inflammation. To fully understand the role of eNOS and NO in the roles of whole-body blood pressure regulation and inflammatory response, the molecular structure and regulatory modifications of eNOS that affect NO production need to be understood.

\section{eNOS structure, co-factors, and phosphorylation}

\section{Structure and cofactors}

The functional form of eNOS is a homodimer [1] with each monomer containing an $\mathrm{N}$-terminal oxygenase and $\mathrm{C}$-terminal reductase domain connected by a central calmodulin (CaM) binding sequence (Fig. 1) [2, 3]. Several crystal structures exist of the different domains from different 
A
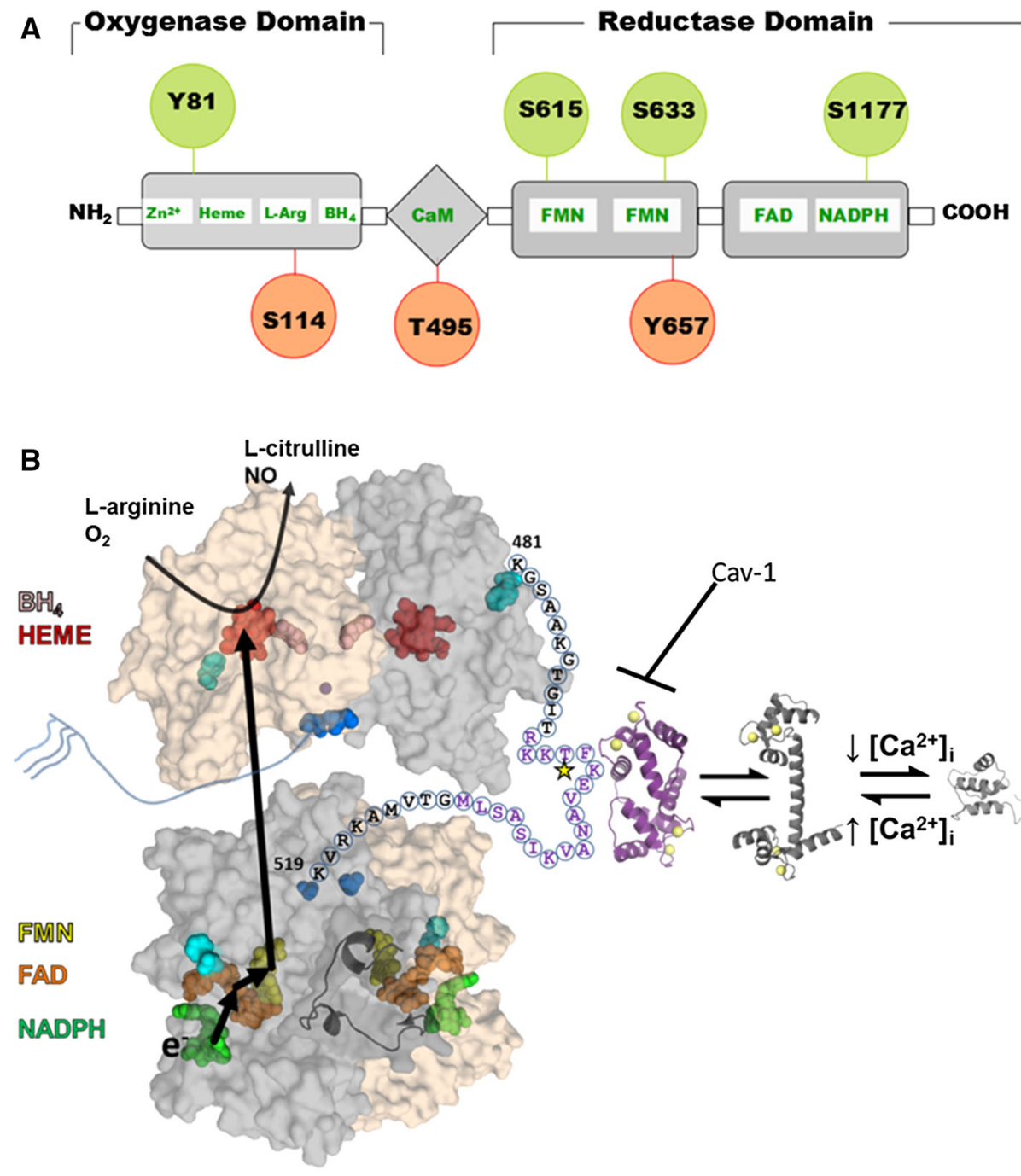

Fig. 1 Structure and regulation of eNOS. a eNOS has oxygenase (residues 98-486), Calmodulin (CaM) binding (491-510), and reductase (756-1002) domains. All three domains contain phosphorylation sites (indicated by circles) that modulate eNOS activity (red for decreased activity and green for increased activity). b Structural model of the full length eNOS. The crystal structure of the human oxygenase domain and a homology model of the reductase domain (using the rat nNOS reductase structure (PDBid: 1TLL) as the template) are shown in a surface representation with one subunit colored gray and the other tan. The autoinhibitory loop (residues 596-640) is rendered as a cartoon for one subunit. Cofactors are

isoforms and organisms; however, the full-length structure of any of the three NOS proteins has yet to be determined. The eNOS dimer is stabilized by 5,6,7,8-tetrahydrobiopterin $\left(\mathrm{H}_{4}\right.$ biopterin) [4] and zinc $[5,6]$ binding to the oxygenase domain. In the human eNOS sequence, zinc binding is coordinated by cysteines 94 and 99 from each monomer and is structurally, but not enzymatically, important. $\mathrm{H}_{4}$ biopterin binds between the interface of heme and the dimer, stabilized by Van der Waals and hydrophobic interactions [7]. In addition to stabilizing the rendered as spheres and colored: NADPH, green; FAD, orange; FMN, yellow; heme, red; $\mathrm{H}_{4}$ biopterin, pink; and zinc, purple. The $\mathrm{N}-($ blue $)$ and $\mathrm{C}$-terminal (cyan) are also rendered as spheres. The linker between the oxygenase and reductase domains is shown for one subunit with the letters indicating the primary sequence. Purple text highlights the CaM binding domain with the star indicating the T495 phosphorylation site. The structure of $\mathrm{CaM}$ bound to a peptide corresponding to the eNOS sequence is shown in purple, and the calcium-bound and unbound $\mathrm{CaM}$ structures are shown in shades of gray. This model is based on that proposed by Garcin et al. [11]

eNOS dimer, $\mathrm{H}_{4}$ biopterin is proposed to modulate the redox potential of the heme prosthetic group.

To start the electron transfer reaction, reduced nicotinamide adenine dinucleotide phosphate (NADPH) binds to the $\mathrm{C}$-terminal reductase domain of one monomer of the eNOS dimer. Within this reductase domain, an electron flows from NADPH to other bound cofactors: flavin adenine dinucleotide (FAD), followed by flavin mononucleotide (FMN). The electron then flows to the heme on the oxygenase domain of the other eNOS monomer. The dimerized 
form is essential for this activity because the electron is transferred between subunits. The reduced heme then catalyzes the synthesis of NO from the substrates of L-arginine and oxygen, creating L-citrulline as a byproduct [8]. A conformational change of the FMN binding domain is postulated such that the FMN domain "swings" from the reductase to the oxygenase domain in order to shuttle the electron between subunits.

The eNOS dimer is inactive without further modification due to two autoinhibitory regions (residues 596-640 (AH1) and 1165-1178 (AH2) $[9,10])$ in the reductase domain that modulate the coupling between the oxygenase and reductase domains. AH1 is postulated to interact with the flexible linker between domains (residues 481-520) and occludes the CaM binding sequence from interacting with CaM. Only the $\mathrm{Ca}^{2+}$-bound conformation of $\mathrm{CaM}$ binds to eNOS, thereby connecting activation of eNOS to intracellular calcium concentration $\left(\left[\mathrm{Ca}^{2+}\right]_{\mathrm{i}}\right)$. $\mathrm{AH} 2$ regulates the interaction of the FMN and NADPH binding regions in the reductase domain; it is postulated to "lock" the FMN domain into a position optimal for electron acceptance and thus must undergo a conformational change to donate an electron to heme $[10,11]$.

The N-terminus of eNOS is proposed to be predominantly unstructured and contains three acylation sites at residues 2, 15, and 26. Glycine 2 is co-translationally myristoylated and is a requirement for membrane localization. Cysteine residues 15 and 26 are post-translationally palmitoylated. The specific role of the palmitoylation is not clear, but stabilization of membrane association and/or sequestration into lipid domains has been proposed [12]. DHHC21, a palmitoyl transferase that has an Asp-His-HisCys motif, palmitoylates eNOS; its depletion affects physiological localization of eNOS, causing a subsequent decrease in NO production [13].

Based on these structural features, there are two ways to regulate eNOS function: modulate the dimer or modulate the coupling of electron transfer from the reductase domain to the oxygenase domain while in the dimeric conformation. Both of these modes of regulation appear to occur variously through cofactor availability (e.g., a decrease in $\mathrm{H}_{4}$ biopterin due to enhanced oxidation), post-translational modifications, cellular localization, and/or protein-protein interactions.

\section{Regulation of eNOS by protein-protein interactions}

In addition to CaM, several other proteins directly bind eNOS and modulate its activity (Table 1). In contrast to the activating role of $\mathrm{CaM}$, one of the most well characterized inhibitors of eNOS activity is caveolin-1 (Cav1). Cav1 is the main coat protein of caveolae, which are membrane microvesicles that harbor membrane-associated proteins in endothelial cells (ECs) [14]. Within caveolae, Cav1 directly associates with eNOS near the CaM-binding sequence and sterically prevents activation by CaM [15], decreasing NO production. Other proteins interact with eNOS; these include heat shock protein 90 (HSP90) [1618 ], NOS interacting protein (NOSIP) [19, 20], $\beta$-actin [21, $22]$, and the alpha subunit of hemoglobin (alpha globin). All of these binding partners cause eNOS translocation from the plasma membrane and activate NO production, except alpha globin. HSP90 binds to eNOS residues 310-323, which are proximal to the Cav1 binding site [16]. Released from Cav1, HSP90 enhances CaM association and phosphorylation on activating residue S1177 via protein kinase B (Akt) [23], (Table 2) thereby increasing NO production. NOSIP binds to the C-terminal region of the oxygenase domain (residues 366-486) [24] and ubiquitinylates eNOS [20], decreasing NO production and marking the enzyme for degradation.

$\beta$-Actin-eNOS association is directly related to oxygen capacity in the microenvironment of the EC. In hyperoxemic conditions, eNOS associates with the actin cytoskeleton via direct binding with $\beta$-actin. Although NO is an effective regulator of blood pressure and vascular function, increased $\mathrm{NO}$ bioavailability in an $\mathrm{O}_{2}$ rich environment often leads to detrimental reactive oxygen species (ROS) formation.

The most recently characterized inhibitory protein partner of eNOS in the microcirculation is alpha globin $[25,26]$. As discussed below, NO bioavailability is decreased by alpha globin expressed in a polarized region of the microvascular endothelial cell known as the myoendothelial junction (MEJ). This localized expression of alpha globin affects the eNOS signaling domain by directly interacting with the oxygenase domain of eNOS to inhibit NO production as well as scavenging NO via the alpha globin heme group.

\section{Activating phosphorylation}

eNOS activity can be enhanced upon phosphorylation at several residues through multiple pathways and kinases (Table 2). The following is a description limited to the sites in which the activation or inhibition has been identified and the structural consequences postulated for each. Additional phosphorylation sites were recently identified (e.g. T33, S53, and S836 through proteomics approaches) [27]; however, their physiological significance has not been investigated.

Three characterized phosphorylation sites that enhance NO production are located in the autoinhibitory regions of the reductase domain (Table 2; S615, S633, and S1177). The introduction of negative charge at each of these sites likely disrupts the interactions of the autoinhibitory regions 
Table 1 eNOS binding partners

\begin{tabular}{|c|c|c|c|}
\hline Protein & $\begin{array}{l}\text { eNOS binding } \\
\text { residues }\end{array}$ & Molecular effect & $\begin{array}{l}\text { NO production } \\
\text { effect }\end{array}$ \\
\hline$\beta$-Actin & $326-333^{a}$ & Hyperoxemia-dependent, stabilizes active form ${ }^{\mathrm{b}}$ & Increased \\
\hline Calmodulin (CaM) & $481-519^{\mathrm{c}}$ & $\begin{array}{l}\mathrm{Ca}^{2+} \text {-dependent, stabilizes dimer for activation, } \\
\text { increases dissociation from membrane }\end{array}$ & Increased \\
\hline Caveolin-1 (Cav1) & $350-358^{\mathrm{d}}$ & $\begin{array}{l}\text { Disrupts CaM binding, sequesters eNOS into } \\
\text { caveolae }^{\mathrm{e}}\end{array}$ & Decreased \\
\hline Hemoglobin, $\alpha$ chain (Alphaglobin) & In oxygenase domain ${ }^{f}$ & Scavenges NO, decreases activation ${ }^{\mathrm{g}}$ & Decreased \\
\hline Heat shock protein 90 (HSP90) & $310-323^{\mathrm{h}}$ & $\begin{array}{l}\text { Releases eNOS from Cav1 } 1^{i} \text {, helps phosphorylation } \\
\text { via Akt recruitment }\end{array}$ & Increased \\
\hline NOS interacting protein (NOSIP) & $366-486^{\mathrm{k}}$ & $\begin{array}{l}\text { Traffics eNOS away from membrane, ubiquitin } \\
\text { ligase activity }^{\mathrm{a}}\end{array}$ & Decreased \\
\hline
\end{tabular}

${ }^{\mathrm{a}}$ Kondrikov et al. [22], ${ }^{\mathrm{b}}$ Kondrikov et al. [21], ${ }^{\mathrm{c}}$ Aoyagi et al. [47], ${ }^{\mathrm{d}}$ Garcia-Cardena et al. [176], ${ }^{\mathrm{e}}$ Bernatchez et al. [157], ${ }^{\mathrm{f}}$ Straub et al. [25], ${ }^{\mathrm{g}} \mathrm{Straub}$ et al. [93], ${ }^{\mathrm{h}} \mathrm{Xu}$ et al. [16], ${ }^{\mathrm{i}}$ Lin et al. [17], ${ }^{\mathrm{j}}$ Takahashi et al. [18], ${ }^{\mathrm{k}}$ Dedio et al. [19], ${ }^{\mathrm{l}}$ Matsumoto et al. [20]

(e.g. S615 and S1177) or modulates the CaM dependence of eNOS activation (e.g. S633). Various eNOS agonists including bradykinin, vascular endothelial growth factor (VEGF), ATP and statins transiently promote phosphorylation at these three sites [28-35] depending on which kinase phosphorylates the site. S615 is phosphorylated by Akt and protein kinase A (PKA) [28], S633 by PKA [31, 35] and AMP-activated kinase (AMPK) [36], and S1177 by numerous kinases, including Akt, PKA, AMPK, cyclic GMP-dependent protein kinase, and $\mathrm{Ca}^{2+}{ }_{-} \mathrm{CaM}$-dependent protein kinase II (CaM kinase II) (Table 2). Mutation of any one of these sites to aspartate as a phosphomimic increased NO production in cells expressing the mutant proteins [20, 28]. In addition to these sites, Y81 is phosphorylated by Src kinase and increases NO production [37, 38]; however, the structural mechanism of activation is unknown.

\section{Inhibitory phosphorylation}

There are three well-characterized phosphorylation sites that inhibit eNOS activity (Table 2; S114, T495, and Y657) with different molecular consequences due to their divergent locations in the eNOS structure. S114, located in the oxygenase domain, is phosphorylated by protein kinase C (PKC) [39] and AMPK [36]. Although contradictory data exist [40, 41], phosphorylation at S114 is more likely to reduce eNOS activity [39, 42]. S114 is located in an unresolved loop in the oxygenase domain crystal structure, away from the heme. Thus, phosphorylation at this site could inhibit activity by preventing interactions between the reductase and oxygenase domain rather than by modulating the redox activity of heme. Alternatively, S114 phosphorylation may modulate protein-protein interactions, as S114 phosphorylation is required for peptidyl- prolyl isomerase binding [43] and may promote eNOS interaction with Cav1.

T495 (Fig. 1b, yellow star) is located in the CaM binding sequence (Fig. 1b, purple text) and is phosphorylated by PKC (in vivo) and AMPK (in vitro) [44, 45] (Table 2). PKC phosphorylation at this site decreases eNOS activity by reducing the affinity of CaM [46]. The structure of CaM bound to the eNOS recognition sequence suggests that the introduction of a negative charge at position 495 destabilizes the CaM-eNOS interaction through repulsion from CaM glutamate residues 7 and 127, although other mechanisms are possible (e.g. destabilizing the helical structure of the CaM binding sequence) [47].

Y657 is phosphorylated by the proline-rich tyrosine kinase 2 (PYK2) (Table 2) and decreases eNOS activity [48]. Without phosphorylation, this particular residue directly interacts with FMN through pi-pi stacking [11]. Its phosphorylation may modulate the reduction potential of FMN or the dynamics of the FMN binding domain, thereby decreasing the efficiency of electron transfer within the eNOS dimer.

\section{Summary of eNOS regulation}

Describing each regulatory element independently provides an unrealistic perspective of eNOS regulation. Phosphorylation or dephosphorylation at each of the aforementioned sites, protein-protein interactions, and the bioavailability of cofactors can occur simultaneously, and all or combinations of these events may regulate eNOS activity. For instance, AMPK phosphorylates both an activating (S1177) and inhibiting (S114) eNOS site. In addition, many stimuli influence multiple pathways that regulate eNOS activity. The well-characterized vasodilator bradykinin stimulates NO synthesis by promoting S1177 phosphorylation [33] and T495 dephosphorylation [49]. Fluid shear stress signals 
Table 2 eNOS phosphorylation regulation

\begin{tabular}{|c|c|c|c|c|}
\hline $\begin{array}{l}\text { Phosphorylation } \\
\text { effect }\end{array}$ & $\begin{array}{l}\text { Phosphorylation } \\
\text { site }\end{array}$ & $\begin{array}{l}\text { eNOS } \\
\text { domain }\end{array}$ & Protein kinases & Phosphorylation stimulators \\
\hline \multirow[t]{4}{*}{ Active } & $\mathrm{Y}_{8} 1^{\mathrm{a}}$ & Oxygenase & $\mathrm{pp} 60^{\mathrm{src}}$ & $\mathrm{H}_{2} \mathrm{O}_{2}$, shear stress \\
\hline & $\mathrm{S} 615^{\mathrm{b}}$ & Reductase & Akt, PKA & Bradykinin, ATP, VEGF, statins ${ }^{c}$ \\
\hline & S633 ${ }^{\mathrm{d}}$ & Reductase & PKA & Shear stress, VEGF, bradykinin, ATP, statins $\mathrm{s}^{\mathrm{b}, \mathrm{c}, \mathrm{e}}$ \\
\hline & $\mathrm{S} 1177^{\mathrm{f}}$ & Reductase & $\begin{array}{l}\text { Akt, PKA, AMPK, } \\
\text { PKG, CaM kinase } \\
\text { II }\end{array}$ & $\begin{array}{l}\text { Shear stress, VEGF, bradykinin, insulin, } \mathrm{H}_{2} \mathrm{O}_{2} \text {, estrogen, adiponectin, } \\
\text { leptin, histamine, thrombin, ischemia, troglitazone, statins } \mathrm{s}^{\mathrm{c}, \mathrm{e}, \mathrm{g}}\end{array}$ \\
\hline \multirow[t]{3}{*}{ Inactive } & $\mathrm{S} 114^{\mathrm{h}}$ & Oxygenase & PKC, AMPK & Shear stress, HDL \\
\hline & $\mathrm{T} 495^{\mathrm{i}}$ & $\begin{array}{l}\mathrm{CaM} \\
\text { binding }\end{array}$ & PKC, AMPK & Insulin, angiotensin \\
\hline & $\mathrm{Y} 657^{\mathrm{j}}$ & Oxygenase & PYK2 & Insulin, angiotensin, shear stress ${ }^{\mathrm{k}}$ \\
\hline
\end{tabular}

${ }^{\mathrm{a}}$ Fulton et al. [37], ${ }^{\mathrm{b}}$ Michell et al. [28], ${ }^{\mathrm{c}}$ Harris et al. [33], ${ }^{\mathrm{d}}$ Boo et al. [31], ${ }^{\mathrm{e}}$ Harris et al. [29], ${ }^{\mathrm{f}}$ Fulton et al. [177], ${ }^{\mathrm{g}}$ Bauer et al. [178], ${ }^{\mathrm{h}}$ Drew et al. [36], ${ }^{\mathrm{i}}$ Michell et al. [44], ${ }^{\mathrm{j}}$ Fisslthaler et al. [48], ${ }^{\mathrm{k}}$ Loot et al. [50]

through a cascade resulting in phosphorylation of eNOS S114 (decreasing NO production), S633 (increasing NO production), Y657 (decreasing NO production), and S1177 (increasing NO production) [48, 50]. This complexity requires a careful and thorough understanding of the cellular system and stimuli, as well as a cumulative understanding of the regulatory processes at work.

\section{Localization of eNOS within the microvascular endothelium}

Within microvascular EC, the vast majority of eNOS is localized to plasma membrane caveolae and associated with Cav1. The targeting of eNOS to the plasma membrane (other NOS isoforms do not localize to the plasma membrane [51]) is an important step in its activation. A number of proteins that regulate eNOS are also targeted to caveolae (for review, see [52]). For example, CaM has a similar pattern of subcellular distribution.

Upon agonist stimulation of ECs, increases in $\left[\mathrm{Ca}^{2+}\right]_{\mathrm{i}}$ cause eNOS dissociation from Cav1 and redistribution to the cytosol [53]. eNOS has no transmembrane domain; thus, post-translational modifications involving fatty acylation (described above) are necessary for targeting and anchoring eNOS to the plasmalemmal caveolae [54-56], increasing bioavailable NO [57].

The lipid composition of caveolar membrane domains is crucial for normal eNOS localization and activation. Normally, cholesterol is enriched in caveolae, and disruption or depletion of cholesterol concentrations causes redistribution of eNOS to an intracellular compartment and decreased NO production [58]. The signaling phosphosphingolipid ceramide is also able to activate eNOS independently of calcium in cultured macrovascular endothelial cells [59], though this mechanism may be different in the microvasculature or in vivo.

In addition to localizing to caveolae and the Golgi membrane, eNOS can be localized to mitochondria, perinuclear regions, and the actin cytoskeleton, but these pools of enzyme contribute less to total NO production compared to the eNOS present in the Golgi membrane and plasmalemmal caveolae. Active eNOS associates with the cytoplasmic cis face of the Golgi apparatus, as evidenced by colocalization with mannosidase $[60,61]$ and association with DHHC21. In the cardiac microvasculature, eNOS expression is higher in total arterial versus venous endothelium, and this difference may be due to a greater level of Golgi association in the coronary arteries [62]. eNOS expression has been shown to be higher in venules than arterioles, but there is still some controversy over the differences between arterial and venous expression and activity of eNOS. Wagner et al. hypothesized that the high eNOS activity in arterial ECs reflects a role in regulating arteriolar tone and that venular-derived NO plays a key role in local thrombosis [63]. The differential regulation and function of eNOS in arterioles and veins is further shown by experiments where, during thrombosis, inhibition of eNOS had no effect on arterioles but induced an increase of leukocyte adhesion in venules [64]. These results could support the idea that there are differences in eNOS function between arterioles and venules, showing the role of eNOS in regulating arteriolar vasodilation and venous inflammation.

\section{Using NO or ROS for vasodilation}

The ultimate goal in understanding production of $\mathrm{NO}$ or reactive nitrogen species is to contextualize the resulting physiological effects. To regulate blood pressure, NO 
produced in ECs relaxes adjacent SMCs, causing dilation and lowering total peripheral resistance. In the resistance arterial vasculature, eNOS is responsible for $20-50 \%$ of dilation [52, 65-72], with endothelium derived hyperpolarization $(\mathrm{EDH})$ accounting for the rest. However, NO appears to be responsible for a higher percentage of dilation in the conduit arteries (up to $100 \%$ of the dilatory component) [73-76]. The contribution of NO bioavailability to dilation declines as the vascular tree progresses from being predominantly a pressure reservoir in large conduit arteries to a highly regulated distribution network in the capillaries, but cannot be simply explained by expression levels, as eNOS is located throughout different vascular beds [77]. Several mechanisms could account for the reduction in reliance on NO bioavailability for dilation in the microcirculation.

\section{Post-translational modifications}

Differential post-translational modifications of eNOS could alter eNOS function and activity in each level of the vascular tree [78-80]. As discussed above, eNOS phosphorylation is a key regulator of eNOS activity. The hemodynamic profile within blood vessels (specifically shear stress) impacts the activity of eNOS. While reports of shear stress throughout the vascular system are variable and depend on the vascular bed, methods of measurement, and animal model, there is agreement that conduit and large arteries are sensitive to shear stress, while areas with low shear stress experience lower NO bioavailability and increased plaque development [81-85]. Indeed, eNOS is upregulated and activated (via phosphorylation of S1177) in rabbit carotid arteries in areas of high shear stress [86]. Further evidence, also using in vivo measurements in rabbits, showed significantly lower expression of eNOS in coronary arteries compared to the aorta, which correlates well with hemodynamic signaling [87]. In porcine vasculature, large conduit arteries that experience increases in wall shear stress positively correlate with eNOS expression [88]. In porcine coronary arteries and arterioles, eNOS expression decreases as the vessels decrease in size [89], although shear stress was not measured in the latter study. This observation highlights apparent distinctions between large and resistance vessels, which include eNOS expression and activation via sensitivity to shear stress. There are currently no well-defined differences in eNOS post-translational modifications from arteries to arterioles that definitively explain the decreased reliance of arterioles on NO for dilation. While some uncertainty exists, vascular beds do regulate eNOS activity through differences in posttranslational modifications; these remain intriguing therapeutic targets in hypertensive pathologies.

\section{Localization}

Subcellular localization of eNOS (see above) [79, 80, 90] could account for the variation in eNOS activity observed. Activation of the caveolar and Golgi pools of eNOS via S1177 phosphorylation occurs by two different mechanisms, with caveolae-associated eNOS being more sensitive to $\left[\mathrm{Ca}^{2+}\right]_{\mathrm{i}}$ fluxes and Golgi-associated eNOS being more sensitive to Akt phosphorylation [61]. Subcellular localization of eNOS affects functionality, and Golgi-localized eNOS is indicated to play an important role in the S-nitrosylation of proteins [91]. Given its close proximity to calcium currents and the larger amount of $\mathrm{NO}$ it produces, plasma membrane-bound eNOS in caveolae has a greater effect on SMC relaxation through cGMP signaling $[61,92]$. Thus eNOS in microvascular ECs may be preferentially located in the Golgi (for S-nitrothiols) or caveolae (for direct NO production) depending on the vessel diameter.

\section{Scavenging}

NO may be present throughout the vasculature but is scavenged, allowing for EDH to dominate the dilatory component of resistance arteries. This observation is supported by recent research identifying alpha globin in EC [93] and noting its enrichment at MEJs. Alpha globin is a potent scavenger of NO, and in ECs, the oxidation state of its heme dictates either NO diffusion into the SMCs or irreversible NO scavenging [26, 94]. eNOS was also found to be enriched at the MEJ and forms a macromolecular complex with alpha globin $[25,94,95]$. When the eNOS/ alpha globin complex was disrupted, the functional outcome was increased NO bioavailability and lower blood pressure in mice [25]. Given the spatial limitations found at the MEJ, and knowing that MEJs increase in frequency from proximal to distal arteries, it is postulated that alpha globin serves as a "sink" for NO, irreversibly scavenging NO production from eNOS [96]. Together, the subcellular localization of eNOS to the MEJ could provide an explanation for the diminished impact of NO in the vasodilation of resistance vasculature, largely due to the increased frequency of MEJs (and alpha globin) that serve as gateways to inhibit NO bioavailability to SMC and allow for EDH to predominate in driving vasodilation.

\section{ROS and vessel size}

Differences in the levels of reactive oxygen species (ROS) and by-products generated by NO between small resistance and large conduit arteries may be responsible for the differences in NO dilatory abilities. ROS could serve as second messengers or activators of selective channels 
within vascular beds [97, 98]. Vascular cells have been shown to have different oxidant profiles across the vascular tree [99]. For example, the cerebral circulation is abundantly supplied with NOX and superoxide, more so than other vascular beds, and these compounds have strong dilating effects on the basilar and middle cerebral arteries [99]. These effects were limited in the aorta, carotid, and mesenteric arteries; but dilation in response to acetylcholine was similar across all vessels in the same study. Although not the focus of this review, other reactive species, including $\mathrm{ONOO}^{-}$, superoxide $\left(\mathrm{O}_{2}^{-}\right)$, and $\mathrm{H}_{2} \mathrm{O}_{2}$ have shown important roles in cellular communication. $\mathrm{ONOO}^{-}$, a nitric oxide-derived oxidant, is formed when $\mathrm{O}_{2}{ }^{-}$and NO react [100], and can not only oxidize DNA, proteins, and lipids, but also interfere with important vascular function by disrupting eNOS function. Oxidation of the $\mathrm{Zn}$ coordination by $\mathrm{ONOO}^{-}$inactivates eNOS by uncoupling its dimer, which leads to synthesis of $\mathrm{O}_{2}{ }^{-}$ rather than $\mathrm{NO}$ [98]. In addition, $\mathrm{ONOO}^{-}$inhibits Akt and increases AMPK-dependent S1177 phosphorylation of eNOS, thereby reducing the bioavailability of NO [97]. $\mathrm{O}_{2}{ }^{-}$is a cytotoxic gaseous molecule that is quickly degraded by superoxide dismutases that turn the radical into either $\mathrm{O}_{2}$ or $\mathrm{H}_{2} \mathrm{O}_{2} \cdot \mathrm{H}_{2} \mathrm{O}_{2}$ plays an important role in the microcirculation, acting as a vasoconstrictor and regulator of blood pressure [101]. However, the mechanisms by which elevated concentrations of $\mathrm{H}_{2} \mathrm{O}_{2}$ lead to vascular dysfunction remain unclear. It is worth noting that $\mathrm{H}_{2} \mathrm{O}_{2}$ has a dual effect on eNOS function, separately stimulating [102] and inhibiting [103] eNOS activity [104]. One effect of $\mathrm{H}_{2} \mathrm{O}_{2}$ is via activation of pp60 $0^{\mathrm{Src}}$, resulting in eNOS phosphorylation at Y418 (via autophosphorylation) and Y215 (an SH2-domain), both of which are inhibited by antioxidants [105]. $\mathrm{H}_{2} \mathrm{O}_{2}$-induced pp60 $0^{\text {Src }}$ activation stimulates eNOS activity via downstream PI3 kinase and KT1 and appears to be both concentration- and time-dependent in its resulting effects; i.e., $\mathrm{H}_{2} \mathrm{O}_{2}$ stimulates activity at lower levels [104] but inhibits eNOS activity at higher levels [104].

\section{Role of eNOS in microcirculatory inflammation}

In addition to causing vasodilation, $\mathrm{NO}$ also has an important anti-inflammatory effect on the microvasculature. NO has been shown to inhibit neutrophil aggregation in vitro [106] and leukocyte adhesion in mesenteric arterioles [107]. Inhibition of eNOS activity has more recently been shown to cause inflammation: chronic inhibition of NO synthesis by L-NAME results in increased expression of leukocyte adhesion molecules, proliferating cell nuclear antigen (an indicator of cellular invasion and proliferation), and chemokines such as monocyte chemotactic protein-1
(MCP-1) [108, 109]. NO inhibition, in turn, leads to characteristics of acute inflammation such as increased microvascular permeability and protein leakage, as well as increased rates of leukocyte adhesion and emigration in venules $[110,111]$. Furthermore, overexpression of eNOS has been shown to inhibit leukocyte adhesion molecule expression and monocyte infiltration in the context of hypercholesterolemia [112].

The central anti-inflammatory role of eNOS-derived NO has also been shown in numerous inflammatory diseases. The expression and activity of eNOS compared to iNOS is a factor in the development and outcome of inflammation $[113,114]$. During gastric ulcers, inflammatory processes are related to an imbalance between NO derived from eNOS and iNOS: eNOS expression was reduced during inflammation, and iNOS expression increased [115-118]. The balance between eNOS/iNOS activity in gastric microcirculation was studied using LYSO-7, a peptide with the ability to activate peroxisome proliferator-activated receptors (PPAR) and to inhibit cyclooxygenase (COX). LYSO-7 restored gastric microcirculatory blood flow and impaired neutrophil influx; however, L-NAME partially inhibited the protective effect of LYSO-7 and led to increased gastric lesions $[113,119]$.

A key initiation event in acute inflammation is leukocyte adhesion to vascular ECs. The expression of adhesion molecules on the surface of activated leukocytes and/or ECs influences the adhesive interaction of leukocytes and ECs in postcapillary venules [120]. eNOS and eNOSderived NO can inhibit this event by regulating the presentation of adhesion molecules, altering their expression in immune cells, or interfering with leukocyte-endothelial cell interaction. eNOS activity inhibits endothelial adhesion molecule expression in the murine lung and attenuates post-ischemic inflammatory injury by suppressing vascular cell adhesion molecule (VCAM) mRNA and protein expression [121]. Furthermore, NO inhibits both the expression of MCP-1 and monocyte adhesion induced by cytokines and oxidized low density lipoproteins (LDL), which also reduces VCAM-1 expression [109, 122-124]. In addition, eNOS activity either inhibits expression of the leukocyte adhesion molecule CD11/CD18 [107] or suppresses the ability of this molecule to bind to the endothelial cell surface [110]. In a severe combined immunodeficiency (SCID)-human mouse model and in human umbilical venous endothelial cells (HUVECs), the inhibition of endogenous NO production results in enhanced rolling and adhesion of human leukocytes. This induced increase in rolling is P- and E-selectin-dependent [124]. Likewise, eNOS knockout mice showed an increased expression of P-selectin [125]. Leukocyte rolling and adhesion in mesenteric venules were blocked by P-selectin-specific antibodies and a high-affinity P-selectin 
ligand [125-127]. These observations show possible antiinflammatory mechanisms of eNOS-derived NO via inhibition of inflammatory processes.

The activation of EC during inflammation interferes with basal EC function and could lead to endothelial dysfunction if inappropriately activated or left unresolved. Endothelial dysfunction includes the loss of NO production, which has been shown after tumor necrosis factor alpha $(\mathrm{TNF} \alpha)$ treatment and subsequent decrease of eNOS expression [128-130] as well as during inflammation via oxidative stress and eNOS uncoupling [115]. Multiple studies show reduced NO bioavailability as a result of oxidative stress. The latter occurs through an imbalance between the production and breakdown of ROS [130] and is speculated to be a major cause underlying endothelial dysfunction. The reduced levels of NO released under inflammatory conditions in response to acetylcholine could thus be a result of ROS interacting with either NO or eNOS. As reported above, $\mathrm{NO}$ can react directly with $\mathrm{O}_{2}{ }^{-}$ to form $\mathrm{ONOO}^{-}$[131]. Diminished eNOS activity or expression through ROS influence has also been demonstrated in an animal model of inflammation [114]. Additionally, $\mathrm{ONOO}^{-}$could lead to eNOS uncoupling by oxidizing the eNOS cofactor $\mathrm{H}_{4}$ biopterin and causing eNOS to synthesize $\mathrm{O}_{2}{ }^{-}$instead of NO [132]. Scavenging of ROS could increase NO bioavailability and present a possible regulation point during inflammatory conditions [114].

\section{Role of eNOS in the microcirculation during sepsis-integrating reactivity and inflammation}

Sepsis is systemic inflammation in response to an infection and is manifested by two or more systemic inflammatory response syndrome criteria [133]. Severe sepsis associated with organ dysfunction is correlated with high morbidity and mortality rates. The pathophysiology of sepsis includes activation of immune cells and inflammatory mediators as well as release of pro-inflammatory cytokines and vasoactive substances such as NO [134]. NO contributes to a sepsis-induced drop in blood pressure by greatly dilating the resistance arteries and decreasing peripheral resistance. A central process during sepsis is the induction of microvascular inflammation, including alteration of EC function [133] that is associated with the increase of both eNOS and iNOS within the first few hours of sepsis [135137], subsequent activation of iNOS, and a decrease of eNOS activity [138]. After 6-48 h of lipopolysaccharide (LPS)-induced sepsis in rats, the expression and activity of eNOS was decreased. Furthermore, eNOS activity was downregulated by diminished phosphorylation in vitro and within a complex animal model [139, 140]. In WT and eNOS KO mice with cecal ligation and puncture (CLP)induced sepsis, increased leukocyte and platelet adhesion was detected. In this study, eNOS KO mice or mice treated with L-NAME had an increase in blood cell recruitment in the hepatic microvasculature following CLP [141]. Treatment with pravastatin, a member of the statin class of drugs used to lower high cholesterol and triglycerides, resulted in increased eNOS function and expression in LPS-injected rats, leading to improvement of eNOS-mediated vessel relaxation [23]. Additionally, overexpression of eNOS led to improved resistance to LPS-induced hypotension and death [142]. Platelet-endothelial cell interactions in mice after LPS injection could be inhibited by application of a NO donor and could be increased by NOS inhibitors or eNOS deficiency [143]. eNOS-derived NO thus seems to have a protective effect by preventing accumulation of platelets and leukocytes, with beneficial results on sepsis development and outcome [144].

\section{Possible pharmacological intervention for NO in the microcirculation}

In clinical settings, the effects of NO have been known for over a century [145]. Before the therapeutic mechanism was known, successful treatment of vascular diseases was achieved by oral doses of nitroglycerin. NO is released from organic molecules by enzymatic processing; e.g., nitroglycerin is converted to NO via xanthine oxidoreductase and mitochondrial aldehyde dehydrogenase [146]. Other organic molecules can deliver NO in physiologic conditions, but applications are more limited because of cytotoxic effects [147]. A classic example, sodium nitroprusside, interacts with hemoglobin to release NO and a relatively large amount of cyanide, thereby undermining its long-term therapeutic effectiveness [148]. NO is a prime target for the treatment of hypo- or hypertension. Increased NO release yields decreased blood pressure (an effective, if short term, treatment of hypertension), while reduced NO release inhibits vasodilation, effectively increasing blood pressure to combat hypotension. Thus, control of eNOS enzymatic activity is an important tool for therapeutic regulation of blood pressure.

Pharmacological intervention to activate or inhibit eNOS represents an important component in treatment of cardiovascular disease, although one that would require tight regulation. All human NOS isoforms (including eNOS, nNOS, and iNOS) require dimerization for efficient production of NO [149-151]. NOS monomers first form a "loose dimer" via inter-molecular cysteine coordination to the heme group. The initial homodimer interaction are subsequently stabilized by binding $\mathrm{BH}_{4}$ and the substrate, 
L-arginine [152]. Some imidazole-containing molecules can bind competitively in the L-arg pocket and prevent dimerization [153, 154]. L-nitroarginine methyl ester (LNAME) is a common reagent for in vivo inhibition of NO production because L-NAME is converted to L-nitroarginine by cellular esterases. L-nitroarginine does not undergo the oxidation reaction that converts L-arg to Lcitrulline, thus inhibiting NO production by limiting substrate/enzyme interaction. These effects are dosedependent and can be overcome by a sufficient saturation with L-arg [150]. Although commonly used as an in vitro inhibitor of eNOS, L-NAME has been used clinically as a therapy for hypotension as a result of septic shock [155, 156]. The target of the therapy is usually iNOS, although LNAME is a general NOS inhibitor because it is a competitive inhibitor of the normal substrate.

Recent advances in manipulating eNOS activity have come through peptide-based regulation. Small peptides (10-20 residues) that mimic the binding sequences of interaction partners can be used to disrupt activating or inhibiting interactions. One method of molecular control of eNOS is by controlling interactions with Cav1 [157, 158]. In caveolae, eNOS is spatially localized with Cav1, facilitating direct interaction. Residues 82-101 (the scaffolding domain) of Cav1 are responsible for binding to eNOS [159]. To further study the interaction, alanine substitution in the Cav1 peptide allowed for functional output studies of critical residues. F92 is the critical residue in Cav1 that inhibits NO production by interrupting an interaction of W445 with $\mathrm{H}_{4}$ biopterin [160]. Mutation of F92 abrogates the inhibitory activity of the Cav1 peptide. In vivo results show that simultaneous delivery of F92 and A92 Cav1 peptides does not abolish NO production completely-the tighter binding affinity of the A92 peptide $(23 \mathrm{nM}$ compared to $49 \mathrm{nM}$ for the F92 peptide) competitively decreases the inhibitory interaction of Cav1 [160, 161].

Another inhibitory regulator of eNOS and NO-induced vasodilation is alpha globin. In the regulation of vascular tone, alpha globin acts in two ways: as a scavenger of NO in the MEJ [26], and as a direct inhibitor of eNOS comparable to Cav1 [93, 157, 159]. Evidence for the direct inhibition of eNOS comes from co-immunoprecipitation of alpha globin and eNOS [25]. In the same study, a synthetic alpha globin peptide mimicking putative binding residues of alpha globin abrogated the interaction between native alpha globin and eNOS in vivo, leading to a significant decrease in blood pressure.

Both peptide therapeutics mentioned have achieved success in vivo $[25,157,160,161]$, but no human clinical data is yet available. However, laboratory data suggest promising results for peptide-based therapy targeting eNOS.

\section{Role of eNOS in red blood cells?}

Until recently, red blood cells (RBCs) have been viewed predominantly as a site of $\mathrm{NO}$ consumption due to the large propensity of hemoglobin to scavenge NO [162-165]. In this context, the possibility of NO production in RBCs was considered unlikely [166]. However, the story may be more complex than previously assumed. NO consumption rates in RBCs are two orders of magnitude lower than cell-free hemoglobin [165], likely due in part to decreased interactions between RBC-bound hemoglobin and NO in the lumen $[167,168]$. Potential barriers to NO scavenging by hemoglobin on RBCs include an RBC-free zone at the periphery of the vessel lumen (where NO is produced) $[163,164]$ and RBC membranes inhibiting NO diffusion into the circulating cell [162].

The presence of NOS in RBCs has been reported by multiple groups with varying details. Circa 2000, studies stated that both eNOS and iNOS are present in RBCs [169, 170], though Kang et al. reported that RBC NOS isoforms were not catalytically active. Furthermore, both groups hypothesized that if functional NOS were expressed on RBCs, the observed ability of RBC hemoglobin to scavenge NO from its surroundings would be compromised by competitive binding of locally-produced NO [170]. In contrast, more recent evidence has been presented to suggest that RBCs universally express a catalytically active eNOS on the inner leaflet of the plasma membrane and in the cytoplasm [166, 171]. RBC eNOS may also play an important role in both routine and diseased vascular function, as its activity and impairment was found to correlate with flow-mediated vessel dilation and endothelial dysfunction, respectively [171]. Other research suggests that RBC eNOS contributes to circulating nitrite levels, which may play a role in blood pressure regulation [172].

Though subject to some controversy, RBCs may be an important source of $\mathrm{NO}$ in the microvasculature. Under normoxic conditions, more NO may be produced in RBCs than any other cellular compartment [171], and NO production by RBC eNOS could have multiple physiological functions. One hypothesis is that RBC eNOS can create an "NO shield" against scavenging by RBCs, preventing interruption of intracellular signaling [171]. Furthermore, shear stress in hypoxic conditions has been indicated to activate RBC eNOS [173], which in turn could play an important role in the regulation of $\mathrm{RBC}$ deformability to ensure adequate perfusion and oxygen distribution [174]. This proposed function in particular suggests the potential for importance of NO from RBC eNOS in regulation of vascular flow. Finally, a broader RBC endocrine-or "erythrocrine"-function has recently been proposed in which RBCs provide systemic NO regulation throughout 
the vasculature (see [175] for details). Thus, an emerging perspective may be that much of the NO interacting with RBCs is produced locally, and that RBCs provide a transport function involved in the localization of $\mathrm{NO}$ signaling.

A major remaining question is to what extent RBCs represent an in vivo sink for vascular NO, and how this role is altered among different physiological regions and pathological states (e.g., across a range of blood oxidation levels or other variations in blood chemistry). Even when considered simply as a sink for NO, the role of RBCs in this context could be more dynamic than initially assumed if RBC eNOS can locally provide a shielding effect against NO scavenging. The variable extent of an RBC eNOS shielding effect could conceivably modulate the impact of NO release from other sources, such as eNOS in the endothelium, by allowing a given RBC to scavenge less or more NO from its surroundings. The possibility of this phenomenon is relevant to the study of NO regulation of local myogenic tone and inflammation. Additionally, the ability of RBCs to influence the speciation of nitrogen oxide metabolites could define the potential of these cells as major signaling players in the vasculature. The ability of RBCs to scavenge and release NO in various settings suggests that they may be capable of activating or inhibiting NO signaling pathways in response to changes in blood chemistry across the vascular tree. Because of the key role of RBCs in the microcirculation, this potentially important site of NO generation requires further investigation in the contexts of vasodilation and inflammation.

\section{Conclusions}

The eNOS enzyme and its key derivative NO play an everexpanding and important role in microvasculature function. Novel pharmacological agents being designed towards the regulation of eNOS make it an exciting area of research, as does the possibility that the enzyme is harbored by cell types beyond the endothelium. Furthermore, ongoing study of reactive oxygen and nitrogen species could inform another layer of eNOS regulation. Further research into eNOS function and NO signaling holds the potential for important physiological understanding and pharmacological opportunities.

Acknowledgments This work was supported by National Institutes of Health Grants HL088554 (BEI), HL107963 (BEI). The American Heart Association provided predoctoral (LAB) and postdoctoral (JTB) fellowships that supported this work. JTB was supported by a National Institutes of Health training Grant (HL007284). Support was also provided by the National Natural Science Foundation of China (XS; 81072063) and China Scholarship Council (XS; 201408210085).

\section{References}

1. Roman LJ, Martásek P, Masters BS (2002) Intrinsic and extrinsic modulation of nitric oxide synthase activity. Chem Rev 102:1179-1190

2. Volkmann N, Martásek P, Roman LJ, Xu XP, Page C, Swift M, Hanein D, Masters BS (2014) Holoenzyme structures of endothelial nitric oxide synthase-an allosteric role for calmodulin in pivoting the FMN domain for electron transfer. J Struct Biol 188:46-54

3. Piazza M, Taiakina V, Guillemette SR, Guillemette JG, Dieckmann T (2014) Solution structure of calmodulin bound to the target peptide of endothelial nitric oxide synthase phosphorylated at Thr495. Biochemistry 53:1241-1249

4. Crane BR, Arvai AS, Ghosh DK, Wu C, Getzoff ED, Stuehr DJ, Tainer JA (1998) Structure of nitric oxide synthase oxygenase dimer with pterin and substrate. Science 279:2121-2126

5. Chen PF, Tsai AL, Wu KK (1994) Cysteine 184 of endothelial nitric oxide synthase is involved in heme coordination and catalytic activity. J Biol Chem 269:25062-25066

6. Chen PF, Tsai AL, Wu KK (1995) Cysteine 99 of endothelial nitric oxide synthase (NOS-III) is critical for tetrahydrobiopterin-dependent NOS-III stability and activity. Biochem Biophys Res Commun 215:1119-1129

7. Fischmann TO, Hruza A, Niu XD, Fossetta JD, Lunn CA, Dolphin E, Prongay AJ, Reichert P, Lundell DJ, Narula SK, Weber PC (1999) Structural characterization of nitric oxide synthase isoforms reveals striking active-site conservation. Nat Struct Biol 6:233-242

8. Hellermann GR, Solomonson LP (1997) Calmodulin promotes dimerization of the oxygenase domain of human endothelial nitric-oxide synthase. J Biol Chem 272:12030-12034

9. Lane P, Gross SS (2000) The autoinhibitory control element and calmodulin conspire to provide physiological modulation of endothelial and neuronal nitric oxide synthase activity. Acta Physiol Scand 168:53-63

10. Lane P, Gross SS (2002) Disabling a C-terminal autoinhibitory control element in endothelial nitric-oxide synthase by phosphorylation provides a molecular explanation for activation of vascular NO synthesis by diverse physiological stimuli. J Biol Chem 277:19087-19094

11. Garcin ED, Bruns CM, Lloyd SJ, Hosfield DJ, Tiso M, Gachhui R, Stuehr DJ, Tainer JA, Getzoff ED (2004) Structural basis for isozyme-specific regulation of electron transfer in nitric-oxide synthase. J Biol Chem 279:37918-37927

12. Prabhakar P, Cheng V, Michel T (2000) A chimeric transmembrane domain directs endothelial nitric-oxide synthase palmitoylation and targeting to plasmalemmal caveolae. J Biol Chem 275:19416-19421

13. Fernández-Hernando $\mathrm{C}$, Fukata $\mathrm{M}$, Bernatchez PN, Fukata $\mathrm{Y}$, Lin MI, Bredt DS, Sessa WC (2006) Identification of Golgilocalized acyl transferases that palmitoylate and regulate endothelial nitric oxide synthase. J Cell Biol 174:369-377

14. Segal SS, Brett SE, Sessa WC (1999) Codistribution of NOS and caveolin throughout peripheral vasculature and skeletal muscle of hamsters. Am J Physiol 277:1167-1177

15. Ju H, Zou R, Venema VJ, Venema RC (1997) Direct interaction of endothelial nitric-oxide synthase and caveolin-1 inhibits synthase activity. J Biol Chem 272:18522-18525

16. Xu H, Shi Y, Wang J, Jones D, Weilrauch D, Ying R, Wakim B, Pritchard KA (2007) A heat shock protein 90 binding domain in endothelial nitric-oxide synthase influences enzyme function. J Biol Chem 282:37567-37574

17. Lin MI, Fulton D, Babbitt R, Fleming I, Busse R, Pritchard KA, Sessa WC (2003) Phosphorylation of threonine 497 in 
endothelial nitric-oxide synthase coordinates the coupling of Larginine metabolism to efficient nitric oxide production. J Biol Chem 278:44719-44726

18. Takahashi S, Mendelsohn ME (2003) Synergistic activation of endothelial nitric-oxide synthase (eNOS) by HSP90 and Akt: calcium-independent eNOS activation involves formation of an HSP90-Akt-CaM-bound eNOS complex. J Biol Chem 278:30821-30827

19. Dedio J, König P, Wohlfart P, Schroeder C, Kummer W, Müller-Esterl W (2001) NOSIP, a novel modulator of endothelial nitric oxide synthase activity. FASEB J. 15:79-89

20. Matsumoto K, Nishiya T, Maekawa S, Horinouchi T, Ogasawara K, Uehara T, Miwa S (2011) The ECS(SPSB) E3 ubiquitin ligase is the master regulator of the lifetime of inducible nitric-oxide synthase. Biochem Biophys Res Commun 409:46-51

21. Kondrikov D, Elms S, Fulton D, Su Y (2010) eNOS-beta-actin interaction contributes to increased peroxynitrite formation during hyperoxia in pulmonary artery endothelial cells and mouse lungs. J Biol Chem 285:35479-35487

22. Kondrikov D, Fonseca FV, Elms S, Fulton D, Black SM, Block ER, Su Y (2010) Beta-actin association with endothelial nitricoxide synthase modulates nitric oxide and superoxide generation from the enzyme. J Biol Chem 285:4319-4327

23. Matsuda N, Hayashi Y, Takahashi Y, Hattori Y (2006) Phosphorylation of endothelial nitric-oxide synthase is diminished in mesenteric arteries from septic rabbits depending on the altered phosphatidylinositol 3-kinase/Akt pathway: reversal effect of fluvastatin therapy. J Pharmacol Exp Ther 319:1348-1354

24. Kone BC, Kuncewicz T, Zhang W, Yu ZY (2003) Protein interactions with nitric oxide synthases: controlling the right time, the right place, and the right amount of nitric oxide. Am J Physiol Renal Physiol. 285:F178-F190

25. Straub AC, Butcher JT, Billaud M, Mutchler SM, Artamonov MV, Nguyen AT, Johnson T, Best AK, Miller MP, Palmer LA, Columbus L, Somlyo AV, Le TH, Isakson BE (2014) Hemoglobin alpha/eNOS coupling at myoendothelial junctions is required for nitric oxide scavenging during vasoconstriction. Arterioscler Thromb Vasc Biol 34:2594-2600

26. Butcher JT, Johnson T, Beers J, Columbus L, Isakson BE (2014) Hemoglobin alpha in the blood vessel wall. Free Radic Biol Med 73:136-142

27. Bian Y, Song C, Cheng K, Dong M, Wang F, Huang J, Sun D, Wang L, Ye M, Zou H (2014) An enzyme assisted RP-RPLC approach for in-depth analysis of human liver phosphoproteome. J Proteomics. 96:253-262

28. Michell BJ, Harris MB, Chen ZP, Ju H, Venema VJ, Blackstone MA, Huang W, Venema RC, Kemp BE (2002) Identification of regulatory sites of phosphorylation of the bovine endothelial nitric-oxide synthase at serine 617 and serine 635. J Biol Chem 277:42344-42351

29. Harris MB, Blackstone MA, Sood SG, Li C, Goolsby JM, Venema VJ, Kemp BE, Venema RC (2004) Acute activation and phosphorylation of endothelial nitric oxide synthase by HMGCoA reductase inhibitors. Am J Physiol Heart Circ Physiol 287:H560-H566

30. Bauer PM, Fulton D, Boo YC, Sorescu GP, Kemp BE, Jo H, Sessa WC (2003) Compensatory phosphorylation and proteinprotein interactions revealed by loss of function and gain of function mutants of multiple serine phosphorylation sites in endothelial nitric-oxide synthase. J Biol Chem 278:14841-14849

31. Boo YC, Sorescu GP, Bauer PM, Fulton D, Kemp BE, Harrison DG, Sessa WC, Jo H (2003) Endothelial NO synthase phosphorylated at SER635 produces NO without requiring intracellular calcium increase. Free Radic Biol Med 35:729-741
32. Boo YC, Sorescu G, Boyd N, Shiojima I, Walsh K, Du J, Jo H (2002) Shear stress stimulates phosphorylation of endothelial nitric-oxide synthase at Ser1179 by Akt-independent mechanisms: role of protein kinase A. J Biol Chem 277:3388-3396

33. Harris MB, Ju H, Venema VJ, Liang H, Zou R, Michell BJ, Chen ZP, Kemp BE, Venema RC (2001) Reciprocal phosphorylation and regulation of endothelial nitric-oxide synthase in response to bradykinin stimulation. $J$ Biol Chem 276:16587-16591

34. Montagnani M, Chen H, Barr VA, Quon MJ (2001) Insulinstimulated activation of eNOS is independent of $\mathrm{Ca} 2+$ but requires phosphorylation by Akt at Ser (1179). J Biol Chem 276:30392-30398

35. Mount PF, Kemp BE, Power DA (2007) Regulation of endothelial and myocardial NO synthesis by multi-site eNOS phosphorylation. J Mol Cell Cardiol 42:271-279

36. Drew BG, Fidge NH, Gallon-Beaumier G, Kemp BE, Kingwell BA (2004) High-density lipoprotein and apolipoprotein AI increase endothelial NO synthase activity by protein association and multisite phosphorylation. Proc Natl Acad Sci USA 101:6999-7004

37. Fulton D, Church JE, Ruan L, Li C, Sood SG, Kemp BE, Jennings IG, Venema RC (2005) Src kinase activates endothelial nitric-oxide synthase by phosphorylating Tyr-83. J Biol Chem 280:35943-35952

38. Fulton D, Ruan L, Sood SG, Li C, Zhang Q, Venema RC (2008) Agonist-stimulated endothelial nitric oxide synthase activation and vascular relaxation. Role of eNOS phosphorylation at Tyr83. Circ Res 102:497-504

39. Kou R, Greif D, Michel T (2002) Dephosphorylation of endothelial nitric-oxide synthase by vascular endothelial growth factor. Implications for the vascular responses to cyclosporin A. J Biol Chem 277:29669-29673

40. Heiss EH, Dirsch VM (2014) Regulation of eNOS enzyme activity by posttranslational modification. Curr Pharm Des 20:3503-3513

41. Kolluru GK, Siamwala JH, Chatterjee S (2010) eNOS phosphorylation in health and disease. Biochimie 92:1186-1198

42. Li C, Ruan L, Sood SG, Papapetropoulos A, Fulton D, Venema RC (2007) Role of eNOS phosphorylation at Ser-116 in regulation of eNOS activity in endothelial cells. Vascul Pharmacol $47: 257-264$

43. Ruan L, Torres CM, Qian J, Chen F, Mintz JD, Stepp DW, Fulton D, Venema RC (2011) Pin1 prolyl isomerase regulates endothelial nitric oxide synthase. Arterioscler Thromb Vasc Biol 31:392-398

44. Michell BJ, Zp Chen, Tiganis T, Stapleton D, Katsis F, Power DA, Sim AT, Kemp BE (2001) Coordinated control of endothelial nitric-oxide synthase phosphorylation by protein kinase $\mathrm{C}$ and the cAMP-dependent protein kinase. J Biol Chem 276:17625-17628

45. Chen ZP, Mitchelhill KI, Michell BJ, Stapleton D, RodriguezCrespo I, Witters LA, Power DA, Ortiz de Montellano PR, Kemp BE (1999) AMP-activated protein kinase phosphorylation of endothelial NO synthase. FEBS Lett 443:285-289

46. Matsubara M, Hayashi N, Jing T, Titani K (2003) Regulation of endothelial nitric oxide synthase by protein kinase C. J Biochem 133:773-781

47. Aoyagi M, Arvai AS, Tainer JA, Getzoff ED (2003) Structural basis for endothelial nitric oxide synthase binding to calmodulin. EMBO J 22:766-775

48. Fisslthaler B, Loot AE, Mohamed A, Busse R, Fleming I (2008) Inhibition of endothelial nitric oxide synthase activity by proline-rich tyrosine kinase 2 in response to fluid shear stress and insulin. Circ Res 102:1520-1528 
49. Fleming I, Fisslthaler B, Dimmeler S, Kemp BE, Busse R (2001) Phosphorylation of $\operatorname{Thr}(495)$ regulates $\mathrm{Ca}(2+) /$ calmodulin-dependent endothelial nitric oxide synthase activity. Circ Res 88:E68-E75

50. Loot AE, Schreiber JG, Fisslthaler B, Fleming I (2009) Angiotensin II impairs endothelial function via tyrosine phosphorylation of the endothelial nitric oxide synthase. J Exp Med 206:2889-2896

51. Nathan C (1992) Nitric oxide as a secretory product of mammalian cells. FASEB J Off Publ Fed Am Soc Exp Biol 6:3051-3064

52. Billaud M, Lohman AW, Johnstone SR, Biwer LA, Mutchler S, Isakson BE (2014) Regulation of cellular communication by signaling microdomains in the blood vessel wall. Pharmacol Rev 66:513-569

53. Prabhakar P, Thatte HS, Goetz RM, Cho MR, Golan DE, Michel T (1998) Receptor-regulated translocation of endothelial nitricoxide synthase. J Biol Chem 273:27383-27388

54. Sessa WC, Barber CM, Lynch KR (1993) Mutation of $\mathrm{N}$-myristoylation site converts endothelial cell nitric oxide synthase from a membrane to a cytosolic protein. Circ Res 72:921-924

55. Garcia-Cardena G, Oh P, Liu J, Schnitzer JE, Sessa WC (1996) Targeting of nitric oxide synthase to endothelial cell caveolae via palmitoylation: implications for nitric oxide signaling. Proc Natl Acad Sci USA 93:6448-6453

56. Shaul PW, Smart EJ, Robinson LJ, German Z, Yuhanna IS, Ying Y, Anderson RG, Michel T (1996) Acylation targets emdothelial nitric-oxide synthase to plasmalemmal caveolae. J Biol Chem 271:6518-6522

57. Liu J, Garcia-Cardena G, Sessa WC (1996) Palmitoylation of endothelial nitric oxide synthase is necessary for optimal stimulated release of nitric oxide: implications for caveolae localization. Biochemistry 35:13277-13281

58. Blair A, Shaul PW, Yuhanna IS, Conrad PA, Smart EJ (1999) Oxidized low density lipoprotein displaces endothelial nitricoxide synthase (eNOS) from plasmalemmal caveolae and impairs eNOS activation. J Biol Chem 274:32512-32519

59. Igarashi J, Thatte HS, Prabhakar P, Golan DE, Michel T (1999) Calcium-independent activation of endothelial nitric oxide synthase by ceramide. Proc Natl Acad Sci USA 96:12583-12588

60. Sessa WC, Garcia-Cardena G, Liu J, Keh A, Pollock JS, Bradley J, Thiru S, Braverman IM, Desai KM (1995) The Golgi association of endothelial nitric oxide synthase is necessary for the efficient synthesis of nitric oxide. J Biol Chem 270:17641-17644

61. Fulton D, Babbitt R, Zoellner S, Fontana J, Acevedo L, McCabe TJ, Iwakiri Y, Sessa WC (2004) Targeting of endothelial nitricoxide synthase to the cytoplasmic face of the Golgi complex or plasma membrane regulates Akt- versus calcium-dependent mechanisms for nitric oxide release. J Biol Chem 279:30349-30357

62. Andries LJ, Brutsaert DL, Sys SU (1998) Nonuniformity of endothelial constitutive nitric oxide synthase distribution in cardiac endothelium. Circ Res 82:195-203

63. Wagner L, Hoey JG, Erdely A, Boegehold MA, Baylis C (2001) The nitric oxide pathway is amplified in venular vs arteriolar cultured rat mesenteric endothelial cells. Microvasc Res 62:401-409

64. Broeders MA, Tangelder GJ, Slaaf DW, Reneman RS, oude Egbrink MG (1998) Endogenous nitric oxide protects against thromboembolism in venules but not in arterioles. Arterioscler Thromb Vasc Biol 18:139-145
65. Bakker EN, Sipkema P (1997) Components of acetylcholineinduced dilation in isolated rat arterioles. Am J Physiol 273:H1848-H1853

66. Billaud M, Lohman AW, Straub AC, Parpaite T, Johnstone SR, Isakson BE (2012) Characterization of the thoracodorsal artery: morphology and reactivity. Microcirculation 19:360-372

67. Koller A, Bagi Z (2004) Nitric oxide and $\mathrm{H}_{2} \mathrm{O}_{2}$ contribute to reactive dilation of isolated coronary arterioles. Am J Physiol Heart Circ Physiol 287:H2461-H2467

68. Koller A, Sun D, Messina EJ, Kaley G (1993) L-arginine analogues blunt prostaglandin-related dilation of arterioles. Am J Physiol 264:H1194-H1199

69. Hwa JJ, Ghibaudi L, Williams P, Chatterjee M (1994) Comparison of acetylcholine-dependent relaxation in large and small arteries of rat mesenteric vascular bed. Am J Physiol 266:H952H958

70. Luksha L, Agewall S, Kublickiene K (2009) Endotheliumderived hyperpolarizing factor in vascular physiology and cardiovascular disease. Atherosclerosis. 202:330-344

71. Nishikawa Y, Stepp DW, Chilian WM (1999) In vivo location and mechanism of EDHF-mediated vasodilation in canine coronary microcirculation. Am J Physiol 277:H1252-H1259

72. Shimokawa H, Yasutake H, Fujii K, Owada MK, Nakaike R, Fukumoto Y, Takayanagi T, Nagao T, Egashira K, Fujishima M, Takeshita A (1996) The importance of the hyperpolarizing mechanism increases as the vessel size decreases in endothelium-dependent relaxations in rat mesenteric circulation. J Cardiovasc Pharmacol 28:703-711

73. Nagao T, Illiano S, Vanhoutte PM (1992) Heterogeneous distribution of endothelium-dependent relaxations resistant to NGnitro-L-arginine in rats. Am J Physiol 263:H1090-H1094

74. Cohen RA, Plane F, Najibi S, Huk I, Malinski T, Garland CJ (1997) Nitric oxide is the mediator of both endothelium-dependent relaxation and hyperpolarization of the rabbit carotid artery. Proc Natl Acad Sci USA 94:4193-4198

75. Chataigneau T, Feletou M, Huang PL, Fishman MC, Duhault J, Vanhoutte PM (1999) Acetylcholine-induced relaxation in blood vessels from endothelial nitric oxide synthase knockout mice. $\mathrm{Br}$ J Pharmacol 126:219-226

76. Garland CJ, Plane F, Kemp BK, Cocks TM (1995) Endotheliumdependent hyperpolarization: a role in the control of vascular tone. Trends Pharmacol Sci 16:23-30

77. Guillot PV, Guan J, Liu L, Kuivenhoven JA, Rosenberg RD, Sessa WC, Aird WC (1999) A vascular bed-specific pathway. J Clin Investig 103:799-805

78. Dudzinski DM, Michel T (2007) Life history of eNOS: partners and pathways. Cardiovasc Res 75:247-260

79. Qian J, Fulton D (2013) Post-translational regulation of endothelial nitric oxide synthase in vascular endothelium. Front Physiol 4:347

80. Michel T, Li GK, Busconi L (1993) Phosphorylation and subcellular translocation of endothelial nitric oxide synthase. Proc Natl Acad Sci USA 90:6252-6256

81. Lam CF, Peterson TE, Richardson DM, Croatt AJ, d'Uscio LV, Nath KA, Katusic ZS (2006) Increased blood flow causes coordinated upregulation of arterial eNOS and biosynthesis of tetrahydrobiopterin. Am J Physiol Heart Circ Physiol 290:H786-H793

82. Chatzizisis YS, Coskun AU, Jonas M, Edelman ER, Feldman CL, Stone PH (2007) Role of endothelial shear stress in the natural history of coronary atherosclerosis and vascular remodeling: molecular, cellular, and vascular behavior. J Am Coll Cardiol 49:2379-2393

83. Lu D, Kassab GS (2011) Role of shear stress and stretch in vascular mechanobiology. J R Soc Interface R Soc 8:1379-1385 
84. Reneman RS, Hoeks AP (2008) Wall shear stress as measured in vivo: consequences for the design of the arterial system. Med Biol Eng Compu 46:499-507

85. Reneman RS, Arts T, Hoeks AP (2006) Wall shear stress-an important determinant of endothelial cell function and structure-in the arterial system in vivo. Discrepancies with theory. J Vasc Res 43:251-269

86. Cheng C, van Haperen R, de Waard M, van Damme LC, Tempel D, Hanemaaijer L, van Cappellen GW, Bos J, Slager CJ, Duncker DJ, van der Steen AF, de Crom R, Krams R (2005) Shear stress affects the intracellular distribution of eNOS: direct demonstration by a novel in vivo technique. Blood 106:3691-3698

87. Dancu MB, Tarbell JM (2007) Coronary endothelium expresses a pathologic gene pattern compared to aortic endothelium: correlation of asynchronous hemodynamics and pathology in vivo. Atherosclerosis 192:9-14

88. Guo X, Kassab GS (2009) Role of shear stress on nitrite and NOS protein content in different size conduit arteries of swine. Acta Physiol 197:99-106

89. Laughlin MH, Turk JR, Schrage WG, Woodman CR, Price EM (2003) Influence of coronary artery diameter on eNOS protein content. Am J Physiol Heart Circ Physiol 284:H1307-H1312

90. Sanchez FA, Savalia NB, Duran RG, Lal BK, Boric MP, Duran WN (2006) Functional significance of differential eNOS translocation. Am J Physiol Heart Circ Physiol 291:H1058H1064

91. Iwakiri Y, Satoh A, Chatterjee S, Toomre DK, Chalouni CM, Fulton D, Groszmann RJ, Shah VH, Sessa WC (2006) Nitric oxide synthase generates nitric oxide locally to regulate compartmentalized protein S-nitrosylation and protein trafficking. Proc Natl Acad Sci USA 103:19777-19782

92. Qian J, Zhang Q, Church JE, Stepp DW, Rudic RD, Fulton DJ (2010) Role of local production of endothelium-derived nitric oxide on cGMP signaling and S-nitrosylation. Am J Physiol Heart Circ Physiol 298:H112-H118

93. Straub AC, Lohman AW, Billaud M, Johnstone SR, Dwyer ST, Lee MY, Bortz PS, Best AK, Columbus L, Gaston B, Isakson BE (2012) Endothelial cell expression of haemoglobin alpha regulates nitric oxide signalling. Nature 491:473-477

94. Straub AC, Zeigler AC, Isakson BE (2014) The myoendothelial junction: connections that deliver the message. Physiology 29:242-249

95. Straub AC, Billaud M, Johnstone SR, Best AK, Yemen S, Dwyer ST, Looft-Wilson R, Lysiak JJ, Gaston B, Palmer L, Isakson BE (2011) Compartmentalized connexin 43 s-nitrosylation/denitrosylation regulates heterocellular communication in the vessel wall. Arterioscler Thromb Vasc Biol 31:399-407

96. Sandow SL, Hill CE (2000) Incidence of myoendothelial gap junctions in the proximal and distal mesenteric arteries of the rat is suggestive of a role in endothelium-derived hyperpolarizing factor-mediated responses. Circ Res 86:341-346

97. Zou MH, Hou XY, Shi CM, Nagata D, Walsh K, Cohen RA (2002) Modulation by peroxynitrite of Akt- and AMP-activated kinase-dependent Ser1179 phosphorylation of endothelial nitric oxide synthase. J Biol Chem 277:32552-32557

98. Zou MH, Shi C, Cohen RA (2002) Oxidation of the zinc-thiolate complex and uncoupling of endothelial nitric oxide synthase by peroxynitrite. J Clin Invest. 109:817-826

99. Miller AA, Drummond GR, Schmidt HH, Sobey CG (2005) NADPH oxidase activity and function are profoundly greater in cerebral versus systemic arteries. Circ Res 97:1055-1062

100. Beckman JS, Beckman TW, Chen J, Marshall PA, Freeman BA (1990) Apparent hydroxyl radical production by peroxynitrite: implications for endothelial injury from nitric oxide and superoxide. Proc Natl Acad Sci USA 87:1620-1624
101. Dayal S, Brown KL, Weydert CJ, Oberley LW, Arning E, Bottiglieri T, Faraci FM, Lentz SR (2002) Deficiency of glutathione peroxidase-1 sensitizes hyperhomocysteinemic mice to endothelial dysfunction. Arterioscler Thromb Vasc Biol 22:1996-2002

102. Drummond GR, Cai H, Davis ME, Ramasamy S, Harrison DG (2000) Transcriptional and posttranscriptional regulation of endothelial nitric oxide synthase expression by hydrogen peroxide. Circ Res 86:347-354

103. Wedgwood S, Steinhorn RH, Bunderson M, Wilham J, Lakshminrusimha S, Brennan LA, Black SM (2005) Increased hydrogen peroxide downregulates soluble guanylate cyclase in the lungs of lambs with persistent pulmonary hypertension of the newborn. Am J Physiol Lung Cell Mol Physiol 289:L660-L666

104. Aschner JL, Foster SL, Kaplowitz M, Zhang Y, Zeng H, Fike CD (2007) Heat shock protein 90 modulates endothelial nitric oxide synthase activity and vascular reactivity in the newborn piglet pulmonary circulation. Am J Physiol Lung Cell Mol Physiol 292:L1515-L1525

105. Ushio-Fukai M, Hilenski L, Santanam N, Becker PL, Ma Y, Griendling KK, Alexander RW (2001) Cholesterol depletion inhibits epidermal growth factor receptor transactivation by angiotensin II in vascular smooth muscle cells: role of cholesterol-rich microdomains and focal adhesions in angiotensin II signaling. J Biol Chem 276:48269-48275

106. Salvemini D, de Nucci G, Gryglewski RJ, Vane JR (1989) Human neutrophils and mononuclear cells inhibit platelet aggregation by releasing a nitric oxide-like factor. Proc Natl Acad Sci USA 86:6328-6332

107. Kubes P, Suzuki M, Granger DN (1991) Nitric oxide: an endogenous modulator of leukocyte adhesion. Proc Natl Acad Sci USA 88:4651-4655

108. Tomita H, Egashira K, Kubo-Inoue M, Usui M, Koyanagi M, Shimokawa H, Takeya M, Yoshimura T, Takeshita A (1998) Inhibition of NO synthesis induces inflammatory changes and monocyte chemoattractant protein-1 expression in rat hearts and vessels. Arterioscler Thromb Vasc Biol 18:1456-1464

109. Zeiher AM, Fisslthaler B, Schray-Utz B, Busse R (1995) Nitric oxide modulates the expression of monocyte chemoattractant protein 1 in cultured human endothelial cells. Circ Res 76:980-986

110. Arndt H, Russell JB, Kurose I, Kubes P, Granger DN (1993) Mediators of leukocyte adhesion in rat mesenteric venules elicited by inhibition of nitric oxide synthesis. Gastroenterology 105:675-680

111. Kubes P, Granger DN (1992) Nitric oxide modulates microvascular permeability. Am J Physiol 262:H611-H615

112. Qian H, Neplioueva V, Shetty GA, Channon KM, George SE (1999) Nitric oxide synthase gene therapy rapidly reduces adhesion molecule expression and inflammatory cell infiltration in carotid arteries of cholesterol-fed rabbits. Circulation 99:2979-2982

113. Santin JR, Daufenback Machado I, Rodrigues SF, Teixeira S, Muscara MN, Lins Galdino S, da Rocha Pitta I, Farsky SH (2013) Role of an indole-thiazolidine molecule PPAR pan-agonist and $\mathrm{COX}$ inhibitor on inflammation and microcirculatory damage in acute gastric lesions. PLoS One 8:e76894

114. Yamashita T, Sakamoto K, Yamanishi H, Totani N, Yamamoto $\mathbf{J}$ (2013) Effect of a free radical scavenger on nitric oxide release in microvessels. Vascul Pharmacol 58:134-139

115. Forstermann U, Sessa WC (2012) Nitric oxide synthases: regulation and function. Eur Heart J 33(829-37):829-837

116. Li D, Laubach VE, Johns RA (2001) Upregulation of lung soluble guanylate cyclase during chronic hypoxia is prevented by deletion of eNOS. Am J Physiol Lung Cell Mol Physiol 281:L369-L376 
117. Guha P, Dey A, Chatterjee A, Chattopadhyay S, Bandyopadhyay SK (2010) Pro-ulcer effects of resveratrol in mice with indomethacin-induced gastric ulcers are reversed by L-arginine. Br J Pharmacol 159:726-734

118. Drapier JC, Wietzerbin J, Hibbs JB Jr (1988) Interferon-gamma and tumor necrosis factor induce the L-arginine-dependent cytotoxic effector mechanism in murine macrophages. Eur $\mathbf{J}$ Immunol 18:1587-1592

119. Santin JR, Uchoa FD, Lima Mdo C, Rabello MM, Machado ID, Hernandes MZ, Amato AA, Milton FA, Webb P, Neves Fde A, Galdino SL, Pitta IR, Farsky SH (2013) Chemical synthesis, docking studies and biological effects of a pan peroxisome proliferator-activated receptor agonist and cyclooxygenase inhibitor. Eur J Pharm Sci 48:689-697

120. Del Maestro RF (1982) Role of superoxide anion radicals in microvascular permeability and leukocyte behaviour. Can J Physiol Pharmacol 60:1406-1414

121. Kaminski A, Pohl CB, Sponholz C, Ma N, Stamm C, Vollmar B, Steinhoff G (2004) Up-regulation of endothelial nitric oxide synthase inhibits pulmonary leukocyte migration following lung ischemia-reperfusion in mice. Am J Pathol 164:2241-2249

122. Cai H, Harrison DG (2000) Endothelial dysfunction in cardiovascular diseases: the role of oxidant stress. Circ Res 87:840-844

123. Cardona-Sanclemente LE, Born GV (1995) Effect of inhibition of nitric oxide synthesis on the uptake of LDL and fibrinogen by arterial walls and other organs of the rat. $\mathrm{Br} \mathrm{J}$ Pharmacol 114:1490-1494

124. Hossain M, Qadri SM, Liu L (2012) Inhibition of nitric oxide synthesis enhances leukocyte rolling and adhesion in human microvasculature. J Inflamm (Lond) 9:28

125. Roman A, McGahren ED (2006) L-NAME-induced neutrophil accumulation in rat lung is not entirely because of interactions with L- and P-selectins or CD18. J Pediatr Surg 41:1743-1749

126. Carden DL, Young JA, Granger DN (1985) Pulmonary microvascular injury after intestinal ischemia-reperfusion: role of P-selectin. J Appl Physiol 1993(75):2529-2534

127. Lefer DJ, Jones SP, Girod WG, Baines A, Grisham MB, Cockrell AS, Huang PL, Scalia R (1999) Leukocyte-endothelial cell interactions in nitric oxide synthase-deficient mice. Am J Physiol 276:H1943-H1950

128. Sun HX, Zeng DY, Li RT, Pang RP, Yang H, Hu YL, Zhang Q, Jiang Y, Huang LY, Tang YB, Yan GJ, Zhou JG (2012) Essential role of microRNA-155 in regulating endothelium-dependent vasorelaxation by targeting endothelial nitric oxide synthase. Hypertension 60:1407-1414

129. Chrissobolis S, Faraci FM (2008) The role of oxidative stress and NADPH oxidase in cerebrovascular disease. Trends Mol Med 14:495-502

130. Chrissobolis S, Miller AA, Drummond GR, Kemp-Harper BK, Sobey CG (2011) Oxidative stress and endothelial dysfunction in cerebrovascular disease. Front Biosci (Landmark Ed) $16: 1733-1745$

131. Touyz RM (2004) Reactive oxygen species and angiotensin II signaling in vascular cells-implications in cardiovascular disease. Braz J Med Biol Res 37:1263-1273

132. Vasquez-Vivar J, Kalyanaraman B, Martasek P, Hogg N, Masters BS, Karoui H, Tordo P, Pritchard KA Jr (1998) Superoxide generation by endothelial nitric oxide synthase: the influence of cofactors. Proc Natl Acad Sci USA 95:9220-9225

133. Aird WC (2003) The role of the endothelium in severe sepsis and multiple organ dysfunction syndrome. Blood 101:3765-3777

134. Giusti-Paiva A, Martinez MR, Felix JV, da Rocha MJ, Carnio EC, Elias LL, Antunes-Rodrigues J (2004) Simvastatin decreases nitric oxide overproduction and reverts the impaired vascular responsiveness induced by endotoxic shock in rats. Shock. 21:271-275

135. Ermert M, Ruppert C, Gunther A, Duncker HR, Seeger W, Ermert L (2002) Cell-specific nitric oxide synthase-isoenzyme expression and regulation in response to endotoxin in intact rat lungs. Lab Invest 82:425-441

136. Liu SF, Newton R, Evans TW, Barnes PJ (1996) Differential regulation of cyclo-oxygenase-1 and cyclo-oxygenase-2 gene expression by lipopolysaccharide treatment in vivo in the rat. Clin Sci (Lond). 90:301-306

137. Scott JA, Mehta S, Duggan M, Bihari A, McCormack DG (2002) Functional inhibition of constitutive nitric oxide synthase in a rat model of sepsis. Am $\mathbf{J}$ Respir Crit Care Med 165:1426-1432

138. McGown CC, Brown NJ, Hellewell PG, Reilly CS, Brookes ZL (2010) Beneficial microvascular and anti-inflammatory effects of pravastatin during sepsis involve nitric oxide synthase III. Br J Anaesth 104:183-190

139. Kamoun WS, Karaa A, Kresge N, Merkel SM, Korneszczuk K, Clemens MG (2006) LPS inhibits endothelin-1-induced endothelial NOS activation in hepatic sinusoidal cells through a negative feedback involving caveolin-1. Hepatology 43:182-190

140. La Mura V, Pasarin M, Meireles CZ, Miquel R, RodriguezVilarrupla A, Hide D, Gracia-Sancho J, Garcia-Pagan JC, Bosch J, Abraldes JG (2013) Effects of simvastatin administration on rodents with lipopolysaccharide-induced liver microvascular dysfunction. Hepatology 57:1172-1181

141. Singer G, Stokes KY, Neil Granger D (2013) Reactive oxygen and nitrogen species in sepsis-induced hepatic microvascular dysfunction. Inflamm Res 62:155-164

142. Yamashita T, Kawashima S, Ohashi Y, Ozaki M, Ueyama T, Ishida T, Inoue N, Hirata K, Akita H, Yokoyama M (2000) Resistance to endotoxin shock in transgenic mice overexpressing endothelial nitric oxide synthase. Circulation 101:931-937

143. Cobb JP, Natanson C, Hoffman WD, Lodato RF, Banks S, Koev CA, Solomon MA, Elin RJ, Hosseini JM, Danner RL (1992) N omega-amino-L-arginine, an inhibitor of nitric oxide synthase, raises vascular resistance but increases mortality rates in awake canines challenged with endotoxin. J Exp Med 176:1175-1182

144. Cerwinka WH, Cooper D, Krieglstein CF, Ross CR, McCord JM, Granger DN (2003) Superoxide mediates endotoxin-induced platelet-endothelial cell adhesion in intestinal venules. Am J Physiol Heart Circ Physiol 284:H535-H541

145. Murrell W (1879) Nitro-Glycerine in angina pectoris. Lancet $1: 80-81$

146. Golwala NH, Hodenette C, Murthy SN, Nossaman BD, Kadowitz PJ (2009) Vascular responses to nitrite are mediated by xanthine oxidoreductase and mitochondrial aldehyde dehydrogenase in the rat. Can J Physiol Pharmacol 87:1095-1101

147. Napoli C, Ignarro LJ (2003) Nitric oxide-releasing drugs. Annu Rev Pharmacol Toxicol 43:97-123

148. Robin ED, McCauley R (1992) Nitroprusside-related cyanide poisoning. Time (long past due) for urgent, effective interventions. Chest 102:1842-1845

149. Klatt P, Pfeiffer S, List BM, Lehner D, Glatter O, Bachinger HP, Werner ER, Schmidt K, Mayer B (1996) Characterization of heme-deficient neuronal nitric-oxide synthase reveals a role for heme in subunit dimerization and binding of the amino acid substrate and tetrahydrobiopterin. J Biol Chem 271:7336-7342

150. Rees DD, Palmer RMJ, Schulz R, Hodson HF, Moncada S (1990) Characterization of 3 inhibitors of endothelial nitric oxide synthase in vitro and in vivo. Br J Pharmacol 101:746-752

151. RodriguezCrespo I, Gerber NC, deMontellano PRO (1996) Endothelial nitric-oxide synthase-expression in Escherichia 
coli, spectroscopic characterization, and role of tetrahydrobiopterin in dimer formation. J Biol Chem 271:11462-11467

152. Pant K, Crane BR (2005) Structure of a loose dimer: an intermediate in nitric oxide synthase assembly. J Mol Biol 352:932-940

153. Sennequier N, Wolan D, Stuehr DJ (1999) Antifungal imidazoles block assembly of inducible NO synthase into an active dimer. J Biol Chem 274:930-938

154. Paige JS, Jaffrey SR (2007) Pharmacologic manipulation of nitric oxide signaling: targeting NOS dimerization and proteinprotein interactions. Curr Top Med Chem 7:97-114

155. Broccard A, Hurni JM, Eckert P, Liaudet L, Schaller MD, Lazor R, Perret C, Feihl F (2000) Tissue oxygenation and hemodynamic response to NO synthase inhibition in septic shock. Shock 14:35-40

156. Avontuur JA, Tutein Nolthenius RP, van Bodegom JW, Bruining HA (1998) Prolonged inhibition of nitric oxide synthesis in severe septic shock: a clinical study. Crit Care Med 26:660-667

157. Bernatchez PN, Bauer PM, Yu J, Prendergast JS, He P, Sessa WC (2005) Dissecting the molecular control of endothelial NO synthase by caveolin-1 using cell-permeable peptides. Proc Natl Acad Sci USA 102:761-766

158. Bucci M, Gratton J-P, Rudic RD, Acevedo L, Roviezzo F, Cirino G, Sessa WC (2000) In vivo deliveryof the caveolin-1 scaffolding domain inhibits nitric oxide synthesis and reduces inflammation. Nat Med 6:1362-1367

159. Sellers SL, Trane AE, Bernatchez PN (2012) Caveolin as a potential drug target for cardiovascular protection. Front Physiol $3: 280$

160. Trane AE, Pavlov D, Sharma A, Saqib U, Lau K, van Petegem F, Minshall RD, Roman LJ, Bernatchez PN (2014) Deciphering the binding of caveolin- 1 to client protein endothelial nitricoxide synthase (eNOS): scaffolding subdomain identification, interaction modeling, and biological significance. J Biol Chem 289:13273-13283

161. Bernatchez P, Sharma A, Bauer PM, Marin E, Sessa WC (2011) A noninhibitory mutant of the caveolin-1 scaffolding domain enhances eNOS-derived NO synthesis and vasodilation in mice. J Clin Investig 121:3747-3755

162. Liu X, Miller MJ, Joshi MS, Sadowska-Krowicka H, Clark DA, Lancaster JR Jr (1998) Diffusion-limited reaction of free nitric oxide with erythrocytes. J Biol Chem 273:18709-18713

163. Butler AR, Megson IL, Wright PG (1998) Diffusion of nitric oxide and scavenging by blood in the vasculature. Biochimica et Biophysica Acta (BBA) General Subjects 1425:168-176

164. Liao JC, Hein TW, Vaughn MW, Huang K-T, Kuo L (1999) Intravascular flow decreases erythrocyte consumption of nitric oxide. PNAS 96:8757-8761

165. Azarov I, Huang KT, Basu S, Gladwin MT, Hogg N, KimShapiro DB (2005) Nitric oxide scavenging by red blood cells as a function of hematocrit and oxygenation. J Biol Chem United States 280:39024-39032
166. Kleinbongard P, Schulz R, Rassaf T, Lauer T, Dejam A, Jax T, Kumara I, Gharini P, Kabanova S, Ozuyaman B, Schnurch HG, Godecke A, Weber AA, Robenek M, Robenek H, Bloch W, Rosen P, Kelm M (2006) Red blood cells express a functional endothelial nitric oxide synthase. Blood United States 107:2943-2951

167. Vaughn MW, Huang KT, Kuo L, Liao JC (2000) Erythrocytes possess an intrinsic barrier to nitric oxide consumption. J Biol Chem 275:2342-2348

168. Helms C, Kim-Shapiro DB (2013) Hemoglobin-mediated nitric oxide signaling. Free Radic Biol Med 61:464-472

169. Jubelin BC, Gierman JL (1996) Erythrocytes may synthesize their own nitric oxide. Am J Hypertens United States 9:1214-1219

170. Kang ES, Ford K, Grokulsky G, Wang YB, Chiang TM, Acchiardo SR (2000) Normal circulating adult human red blood cells contain inactive NOS proteins. J Lab Clin Med United States 135:444-451

171. Cortese-Krott MM, Rodriguez-Mateos A, Sansone R, Kuhnle GG, Thasian-Sivarajah S, Krenz T, Horn P, Krisp C, Wolters D, Heiss C, Kroncke KD, Hogg N, Feelisch M, Kelm M (2012) Human red blood cells at work: identification and visualization of erythrocytic eNOS activity in health and disease. Blood United States 120:4229-4237

172. Wood KC, Cortese-Krott MM, Kovacic JC, Noguchi A, Liu VB, Wang X, Raghavachari N, Boehm M, Kato GJ, Kelm M, Gladwin MT (2013) Circulating blood endothelial nitric oxide synthase contributes to the regulation of systemic blood pressure and nitrite homeostasis. Arterioscler Thromb Vasc Biol 33:1861-1871

173. Ulker P, Sati L, Celik-Ozenci C, Meiselman HJ, Baskurt OK (2009) Mechanical stimulation of nitric oxide synthesizing mechanisms in erythrocytes. Biorheology 46:121-132

174. Bor-Kucukatay M, Wenby RB, Meiselman HJ, Baskurt OK (2003) Effects of nitric oxide on red blood cell deformability. Am J Physiol Heart Circ Physiol United States 284:H1577H1584

175. Cortese-Krott MM, Kelm M (2014) Endothelial nitric oxide synthase in red blood cells: key to a new erythrocrine function? Redox Biol 2:251-258

176. Garcia-Cardena G, Fan R, Stern DF, Liu J, Sessa WC (1996) Endothelial nitric oxide synthase is regulated by tyrosine phosphorylation and interacts with caveolin-1. J Biol Chem 271:27237-27240

177. Fulton D, Gratton JP, McCabe TJ, Fontana J, Fujio Y, Walsh K, Franke TF, Papapetropoulos A, Sessa WC (1999) Regulation of endothelium-derived nitric oxide production by the protein kinase Akt. Nature 399:597-601

178. Bauer PM, Fulton D, Boo YC, Sorescu GP, Kemp BE, Jo H, Sessa WC (2003) Compensatory phosphorylation and proteinprotein interactions revealed by loss of function and gain of function mutants of multiple serine phosphorylation sites in endothelial nitric-oxide synthase. J Biol Chem 278:14841-14849 